\title{
Presence of hepatitis B virus in synovium and its clinical significance in rheumatoid arthritis
}

Yu-Lan Chen ${ }^{1}$, Jun Jing ${ }^{1}$, Ying-Qian Mo', Jian-Da Ma', Li-Juan Yang ${ }^{1}$, Le-Feng Chen ${ }^{1}$, Xiang Zhang ${ }^{2}$, Tao Yan ${ }^{3}$, Dong-Hui Zheng ${ }^{1}$, Frank Pessler ${ }^{4,5^{*}}$ and Lie Dai ${ }^{*}$

\begin{abstract}
Background: Previous studies have revealed that hepatitis B virus (HBV) infection may be related to rheumatoid arthritis (RA), but there are no studies on the presence of HBV antigens or nucleic acid in synovium from patients with RA with HBV infection. In the present study, we investigated the presence of HBV in the synovium and its clinical significance in RA.

Methods: Fifty-seven consecutive patients with active RA (Disease Activity Score 28-joint assessment based on C-reactive protein $\geq 2.6$ ) and available synovial tissue who had completed 1 year of follow-up were recruited from a prospective cohort. The patients were divided into chronic HBV infection (CHB, $n=11)$ and non-CHB groups according to baseline HBV infection status. Clinical data were collected at baseline and at 1-, 3-, 6-, and 12-month follow-up. Radiographic changes of hand/wrist at baseline and month 12 were assessed with the Sharp/van der Heijde-modified Sharp score (mTSS). HBV in synovium was determined by immunohistochemical staining for hepatitis B virus surface antigen and hepatitis B virus core antigen ( $\mathrm{HBCAg}$ ) and by nested PCR for the HBV $S$ gene.

Results: HBCAg was found in the synovium of patients with RA with CHB (7 of 11,64\%), which was confirmed by PCR for the HBV $S$ gene. Compared with the non-CHB group, more CD68-positive macrophages, CD20-positive B cells, and CD15-positive neutrophils infiltrated the synovium in the CHB group (all $p<0.05$ ). There were smaller improvements from baseline in most disease activity indicators mainly at month 12 , and a significantly higher percentage of CHB patients experienced 1-year radiographic progression ( $\Delta \mathrm{mTSS} \geq 0.5$ unit/yr, 64\% vs. 26\%, $p$ $=0.024)$. Multivariate logistic regression analysis showed that CHB status (OR 14.230, 95\% Cl 2.213-95.388; $p=0.006)$ and the density of synovial CD68-positive macrophages (OR 1.002, 95\% Cl 1.001-1.003; $p=0.003$ ) were independently associated with 1-year radiographic progression.
\end{abstract}

Conclusions: The presence of HBV in RA synovium may be involved in the pathogenesis of local lesions and exacerbate disease progression in RA.

Keywords: Hepatitis B virus, Rheumatoid arthritis, Radiographic progression, Synovium, Synovial biopsy

\footnotetext{
* Correspondence: frank.pessler@helmholtz-hzi.de; dailie@mail.sysu.edu.cn

${ }^{4}$ TWINCORE Center for Experimental and Clinical Infection Research,

Hannover, Germany

'Department of Rheumatology, Sun Yat-Sen Memorial Hospital, Sun Yat-Sen

University, Guangzhou, People's Republic of China

Full list of author information is available at the end of the article
}

(c) The Author(s). 2018 Open Access This article is distributed under the terms of the Creative Commons Attribution 4.0 International License (http://creativecommons.org/licenses/by/4.0/), which permits unrestricted use, distribution, and reproduction in any medium, provided you give appropriate credit to the original author(s) and the source, provide a link to the Creative Commons license, and indicate if changes were made. The Creative Commons Public Domain Dedication waiver (http://creativecommons.org/publicdomain/zero/1.0/) applies to the data made available in this article, unless otherwise stated. 


\section{Background}

Rheumatoid arthritis (RA) is a chronic systemic autoimmune disorder characterized by synovitis and bone/cartilage destruction [1]. Even though the etiology of RA remains unknown, there is evidence that it results from a combination of genetic predisposition and environmental factors, especially infectious agents such as Epstein-Barr virus, cytomegalovirus, and Proteus mirabilis [2]. Molecular mimicry on the basis of amino acid similarities shared by viral and self-antigens has long been proposed as a pathogenic mechanism for RA [3]. However, the pathogenicity of other infectious agents linked to RA remains to be identified.

Hepatitis B virus (HBV) infection is a major cause of chronic liver diseases, such as liver cirrhosis and hepatocellular carcinoma. The genome of this DNA virus encompasses four partially overlapping open reading frames, of which the $p r e-S / S$ region encodes the viral surface antigen (HBsAg) and the pre-core/core gene encodes the e antigen (HBeAg) and the core antigen (HBcAg) [4]. HBV infects not only human hepatocytes but also diverse extrahepatic tissues such as lymph nodes, kidney, skin, colon, stomach and pancreas, which leads to extrahepatic manifestations in patients with HBV infection or HBV-related diseases such as glomerulonephritis and polyarteritis nodosa [5]. Some patients with symptoms induced by recombinant hepatitis $\mathrm{B}$ vaccination were reported to fulfil the 1987 revised criteria of the American College of Rheumatology (ACR) for RA and required disease-modifying anti-rheumatic drug (DMARD) therapy [6]. The serum HBsAg positivity reported in our previous study was $11.2 \%$ in Chinese patients with RA, compared with $8.7 \%$ in the age-matched Chinese general population [7]. In agreement with this, a recent study revealed a higher HBV period prevalence in 38,969 patients with RA than in 701,476 non-RA control subjects in Taiwan [8], which further supported the hypothesis that HBV infection has a subtle association with RA. In the 1970s, Schumacher et al. first reported the presence of HBV in the synovium of two patients with arthritis with HBV infection using direct immunofluorescence, and they also found virus particles mainly in synovial lining cells and vascular endothelium by electron microscopy [9]. A case report published in 2006 described a patient with knee osteoarthritis who had positive serum $\mathrm{HBsAg}$ and $\mathrm{HBeAg}$ experienced rapidly destructive knee arthropathy; in that report, immunohistochemical staining revealed diffuse HBsAg expression in the patient's synovium [10]. Nevertheless, no study regarding the presence of $\mathrm{HBV}$ in the synovium from patients with RA has been reported. The aim of this study was to investigate the frequency of $\mathrm{HBV}$ infection in the synovium of patients with coexisting $\mathrm{RA}$ and to determine its influence on histopathological characteristics of synovitis as well as clinical and radiographic outcomes in RA.

\section{Methods \\ Study patients}

Consecutive patients with RA who fulfilled the 1987 ACR revised criteria [11] or the 2010 ACR/European League Against Rheumatism (EULAR) criteria [12] for RA classification were retrospectively recruited from a prospective RA cohort $(n=239)$ in the Department of Rheumatology at Sun Yat-Sen Memorial Hospital from June 2013 to August 2016. The inclusion criteria in this study also included the following: active disease, defined as the Disease Activity Score in 28 joints with four variables including C-reactive protein (DAS28-CRP) $\geq 2.6$; availability of synovial tissue at baseline passing quality criteria (at least six pieces containing lining layer and sublining area to a depth of at least 1 high-power microscopic field, 400× magnification); and completion of at least 1 year of follow-up. The exclusion criteria were as follows: overlap with other autoimmune diseases (e.g., systemic lupus erythematosus, scleroderma, dermatomyositis, polyarteritis nodosa); presence of liver cirrhosis or hepatocellular carcinoma, Wilson's disease, steatohepatitis, hemochromatosis, or schistosomiasis japonica; concomitant infection with hepatitis $C$ virus, hepatitis $D$ virus, human immunodeficiency virus, or other serious infection, organ dysfunction, or malignancy; and being lactating, pregnant, or planning to become pregnant. All participants gave their written informed consent before clinical data collection. The study was approved by the Medical Ethics Committee of Sun Yat-Sen Memorial Hospital (identifier SYSEC-2009-06).

\section{Serology and virology of HBV infection and patient grouping}

Serological markers of HBV infection, including HBsAg, antibodies to hepatitis B surface antigen (anti-HBs), $\mathrm{HBeAg}$, antibodies to hepatitis $\mathrm{B}$ e antigen (anti-HBe), and antibodies to hepatitis B core antigen (anti-HBc), were tested in all patients with RA by electrochemiluminescence immunoassay (Roche Diagnostics, Mannheim, Germany). Serum HBV DNA level was measured with a commercially available qRT-PCR kit (Da An Gene Co., Ltd. of Sun Yat-Sen University, Guangdong, China), with a limit of detection of $500 \mathrm{IU} / \mathrm{ml}$. The diagnosis of HBV infection fulfilled the Chinese guidelines for prevention and treatment of chronic hepatitis $B$ [13]. Chronic hepatitis $B$ virus infection $(\mathrm{CHB})$ was defined as positive HBsAg and (or) HBV DNA persisting in serum for $\geq 6$ months. Resolved $\mathrm{HBV}$ infection was defined as negative HBsAg and HBV DNA in serum but positive anti-HBc. Non-HBV infection was defined as negative $\mathrm{HBsAg}, \mathrm{HBeAg}$, anti-HBe, anti-HBc, and $\mathrm{HBV}$ 
DNA in serum, regardless of anti-HBs status. According to the baseline HBV infection status, all patients were divided into a $\mathrm{CHB}$ group and a non-CHB group (resolved HBV and non-HBV).

\section{Clinical data collection}

Demographic and clinical data were collected at baseline and at 1-, 3-, 6-, and 12-month follow-up as in our previous report and modified according to the 2017 EULAR recommendations [14], including the 28-joint tender and swollen joint count (28TJC and 28SJC, respectively), patient and provider global assessment of disease activity (PtGA and PrGA, respectively), pain visual analogue scale (Pain VAS), the Stanford Health Assessment Questionnaire Disability Index (HAQ-DI), erythrocyte sedimentation rate (ESR), C-reactive protein (CRP), serum rheumatoid factor (RF), and anti-cyclic citrullinated peptide antibody (ACPA). Disease activity was assessed with DAS28-CRP, the Disease Activity Score in 28 joints with four variables including ESR (DAS28-ESR), the Simplified Disease Activity Index (SDAI), the Clinical Disease Activity Index (CDAI), and the Routine Assessment of Patient Index Data 3 (RAPID3).

HBV serological markers and HBV DNA levels were evaluated in all patients with RA at baseline and every 1-3 months during follow-up in the $\mathrm{CHB}$ group. These parameters in the non-CHB group were reexamined if aminotransferase activity was elevated during follow-up. Liver function, including alanine aminotransferase (ALT, $\mathrm{U} / \mathrm{L}$, normal range 5-40 U/L) and aspartate transaminase (AST, U/L, normal range 5-40 U/L), as well as bilirubin as clinically indicated, was also tested at each visit.

\section{Radiographic assessments}

Radiographic assessments of bilateral hands and wrists (anteroposterior view) were done at baseline and month 12. Joint damage, including joint erosion (JE) and joint space narrowing (JSN), was assessed with the Sharp/van der Heijde modified Sharp score (mTSS) by two experienced observers (JDM from the Department of Rheumatology and $\mathrm{XZ}$ from the Department of Radiology) who were blinded to clinical data as we described previously [15]. Reliability and agreement were assessed using an intraclass correlation coefficient (ICC): the mean ICC for interobserver agreement was 0.90 . Bony erosion was defined when a cortical break was detected by radiography [16]. Radiographic progression was defined as a change of mTSS $(\Delta \mathrm{mTSS}) \geq$ 0.5 unit after 1 year [17]. Rapid radiographic progression was defined as $\triangle \mathrm{mTSS} \geq 5$ units after 1 year [18].

\section{Immunohistochemical and synovitis assessments}

All synovial tissues in this study were obtained by closed Parker-Pearson needle biopsy from actively inflamed knee joints of patients with RA $[19,20]$. Samples were fixed in $10 \%$ neutral formalin and embedded in paraffin. Serial sections of synovium ( $3 \mu \mathrm{m}$ thick) were stained with H\&E and immunohistochemically stained according to a three-step immunoperoxidase method. Sections were stained with anti-human HBsAg (Novocastra Laboratories Ltd., Newcastle Upon Tyne, UK; and Maixin Biotechnologies Ltd., Fuzhou, Fujian, China), HBcAg (Dako, Carpinteria, CA, USA), and the following commercial antibody preparations (Life Technologies, Carlsbad, CA, USA; and Novocastra Laboratories Ltd., Newcastle Upon Tyne, UK) according to standard staining protocols: anti-CD20 (clone L26, B cells), anti-CD38 (clone SPC32, plasma cells), anti-CD3 (clone PS1, T cells), anti-CD68 (clone KP1, macrophages), anti-CD15 (clone My1, neutrophils), and anti-CD34 (clone QB End/10, vascular endothelial cells). All antibodies were mouse monoclonal antibodies, except anti-HBcAg (rabbit polyclonal antibodies). Parallel sections were incubated with irrelevant, isotype, and concentration-matched monoclonal antibodies as a negative control, and liver tissues from patients with HBV-related hepatocellular carcinoma were used as a positive control. Histopathological changes in $\mathrm{H} \& \mathrm{E}$-stained sections were graded according to the Krenn synovitis score [21-23]. The densities of cells with positive staining for CD3, CD15, CD20, CD38, and CD68 and the microvessel count (MVC; confirmed by the presence of CD34-positive endothelial cells in vessels with diameter $\leq 8$ erythrocytes) were determined using manual counting by two independent trained investigators (LFC from the Department of Rheumatology and TY from Zhongshan School of Medicine) who were blinded to the clinical data. The densities are given as cells per square millimeter [20,24].

\section{Detection of HBV DNA in the synovium}

The HBV $S$ gene was detected by nested PCR as described previously [25]. HBV DNA was extracted from about $30 \mathrm{mg}$ (obtained from approximately 20 sections, $5 \mu \mathrm{m}$ thick, not attached to glass slides) of paraffin-embedded synovium with the RecoverAll ${ }^{\text {Tw }}$ total nucleic acid isolation kit (Life Technologies). Liver tissue from patients with HBV-related hepatocellular carcinoma was included as a positive control. Amplification was carried out in a 50- $\mu \mathrm{l}$ reaction volume containing $3 \mu \mathrm{l}$ of forward and reverse primers $(10 \mu \mathrm{M}), 40 \mathrm{ng}$ of DNA template, and $25 \mu \mathrm{l}$ of $2 \times$ KAPA HiFi HotStart ReadyMix (Kapa Biosystems, Wilmington, MA, USA). The following thermocycles were used: $95^{\circ} \mathrm{C}$ for 3 minutes, followed by 35 cycles of $98{ }^{\circ} \mathrm{C}$ for 20 seconds, $65^{\circ} \mathrm{C}$ for 15 seconds, and $72{ }^{\circ} \mathrm{C}$ for $1 \mathrm{mi}$ nute, with a final extension at $72{ }^{\circ} \mathrm{C}$ for 1 minute. The PCR products were then resolved by gel electrophoresis (Life Technologies). DNA bands were visualized by ultraviolet fluorescence. PCR products were sequenced in both directions on an ABI 3730 XL Automated DNA Sequencer with the ABI BigDye Terminator v3.1 cycle sequencing 
kit (Applied Biosystems, Foster City, CA, USA). The sequences were aligned using the Basic Local Alignment Search Tool (National Center for Biotechnology Information website https://blast.ncbi.nlm.nih.gov/Blast.cgi) to confirm the identity of the HBV $S$ gene.

\section{Statistical analysis}

IBM SPSS Statistics 20.0 for Windows software (IBM, Armonk, NY, USA) was used for statistical analyses. For continuous variables, the Mann-Whitney $U$ test or Kruskal-Wallis analysis of variance on ranks between two groups or among three groups was used, and descriptive statistics (median, interquartile range (IQR)) were calculated. The Wilcoxon matched-pairs signed-rank sum test was used to compare the differences of continuous variables between disease activity indicators at baseline and each visit. For categorical variables, the Chi-square test or Fisher's exact test was used, and indicators are presented as frequencies and percentages. Spearman's rank-order correlation test was used to assess the relationship between serum levels of HBV DNA and RA disease characteristics in the $\mathrm{CHB}$ group. Logistic regression analyses were performed to identify risk factors for 1-year radiological progression by adjusting for confounding factors. Variables were included in the equation when $p<0.05$ or removed when $p>0.10$ following the stepwise forward selection rule. A two-tailed $p<0.05$ was considered statistically significant.

\section{Results}

\section{Baseline characteristics}

Baseline characteristics of the 57 included patients with RA are shown in Table 1. There were 43 (75\%) female patients. The median age of all patients was 51 years and the median disease duration was 24 months. Eighty-four percent of patients had bony erosion at baseline, and $61 \%$ of the patients were without glucocorticosteroid or DMARD therapy in the 6 months before entry into the study (treatment-naïve). According to HBV infection status at baseline, there were 11 (19\%), 22 (39\%), and $24(42 \%)$ patients with $\mathrm{CHB}$, resolved HBV, and non-HBV infection, respectively. In the CHB group, eight patients had detectable serum HBV DNA at baseline, ranging from $5.00 \times 10^{2} \mathrm{IU} / \mathrm{ml}$ to $6.96 \times 10^{7} \mathrm{IU} / \mathrm{ml}$; four patients had positive HBeAg, but only one had abnormal liver function (AST $50 \mathrm{U} / \mathrm{L}$ and ALT $66 \mathrm{U} / \mathrm{L}$ ). All CHB patients showed persistently positive HBsAg in serum during the 1-year follow-up.

\section{HBV detection in synovium}

The results of immunohistochemical staining of synovial tissue were negative for HBsAg in all samples from both the $\mathrm{CHB}$ and the non-CHB groups, but they were positive for HBcAg in synovial tissues from seven CHB patients, of whom five had detectable serum HBV DNA (ranging from $5.00 \times 10^{2} \mathrm{IU} / \mathrm{ml}$ to $6.96 \times 10^{7} \mathrm{IU} / \mathrm{ml}$ ) and two had positive serum $\mathrm{HBeAg}$. $\mathrm{HBcAg}$ immunoreactivity was observed in CD38-positive plasma cells and CD68-positive macrophages in the sublining area, located mainly in the cytoplasm (Fig. 1a and b). HBcAg was not detected in the other four patients with $\mathrm{CHB}$ or in the non-CHB patients.

The presence of the HBV $S$ gene was tested by nested PCR in synovial tissue from four patients with $\mathrm{CHB}$ with positive synovial $\mathrm{HBcAg}$ immunoreactivity, two patients with resolved HBV infection, and two non-HBV patients. The HBV $S$ gene was detected only in the four CHB samples (Fig. 1c). Further DNA sequencing of PCR products confirmed the specificity of amplification, demonstrating the presence of HBV DNA in the synovium from patients with $\mathrm{RA}$ and $\mathrm{CHB}$.

\section{HBV infection and histopathological synovitis}

Synovial histopathological features were compared in patients with RA with and without CHB (Table 2). Compared with non-CHB synovium, significantly higher densities of total and sublining CD68-positive macrophages, CD20-positive B cells, and CD15-positive neutrophils were observed in the CHB specimens (all $p<0.05$ ). Further comparison was performed between CHB synovium with and without positive $\mathrm{HBcAg}$. Remarkably, compared with $\mathrm{CHB}$ synovium with negative $\mathrm{HBcAg}(n=4)$, there were significantly more MVC, sublining CD68-positive macrophages and $\mathrm{CD} 20$-positive $\mathrm{B}$ cells infiltrating the $\mathrm{CHB}$ synovium with positive $\mathrm{HBcAg}(n=7)$, with a higher subscore of synovial stroma activation (all $p<0.05$ ).

\section{Clinical responses}

All patients were treated according to the "treat-to-target" strategy, the patient's willingness, and the patient's HBV infection status [26, 27]. Ten (91\%) patients in the CHB group accepted antiviral prophylaxis, including entecavir $(n=4)$, lamivudine $(n=4)$, and adefovir $(n=2)$. Compared with the non-CHB group, patients with RA with $\mathrm{CHB}$ showed significantly lower levels of most disease activity indicators at baseline, including TJC28, PtGA, PrGA, Pain VAS, DAS28-CRP, DAS28-ESR, SDAI, CDAI, and RAPID3 (all $p<0.05$ ) (Table 1). During 1-year follow-up, significant improvement from baseline was observed in disease activity indicators at each visit (all $p<0.001$ ) (Additional file 1). However, compared with the non-CHB group, patients with RA with $\mathrm{CHB}$ experienced smaller improvements from baseline in most disease activity indicators, mainly at month 12, including PtGA, PrGA, Pain VAS, HAQ-DI, DAS28-CRP, SDAI, and CDAI, especially RAPID3 at almost each point except month 3 (all $p<0.05$ ) (Fig. 2). There were no significant differences in baseline characteristics, initial therapy, or improvements of disease 
Table 1 Baseline characteristics of patients

\begin{tabular}{|c|c|c|c|c|}
\hline Parameters & $\begin{array}{l}\text { All patients } \\
(n=57)\end{array}$ & $\begin{array}{l}\text { CHB group } \\
(n=11)\end{array}$ & $\begin{array}{l}\text { Non-CHB group } \\
(n=46)\end{array}$ & $p$ Value \\
\hline \multicolumn{5}{|c|}{ Demographic characteristics } \\
\hline Female, $n(\%)$ & $43(75)$ & $7(64)$ & $36(78)$ & 0.311 \\
\hline Age, yr & $51(45-59)$ & $49(41-53)$ & $52(46-60)$ & 0.311 \\
\hline Disease duration, mo & $24(7-102)$ & $120(6-120)$ & $24(7-72)$ & 0.345 \\
\hline Smoking, $n(\%)$ & $12(21)$ & $2(18)$ & $10(22)$ & 0.795 \\
\hline \multicolumn{5}{|l|}{ Disease activity indicators } \\
\hline TJC28 & $9(5-16)$ & $5(2-9)$ & $11(5-16)$ & 0.021 \\
\hline SJC28 & $6(3-9)$ & $5(2-8)$ & $6(4-10)$ & 0.300 \\
\hline PtGA & $6(5-8)$ & $5(3-6)$ & $6(5-8)$ & 0.007 \\
\hline PrGA & $6(4-7)$ & $5(3-6)$ & $6(5-8)$ & 0.006 \\
\hline Pain VAS & $5(4-6)$ & $4(2-5)$ & $6(4-7)$ & 0.023 \\
\hline$C R P, m g / L$ & $32.0(14.8-61.0)$ & $24.9(15.4-66.8)$ & $32.6(14.2-55.6)$ & 0.656 \\
\hline $\mathrm{ESR}, \mathrm{mm} / \mathrm{h}$ & $68(45-98)$ & $63(37-105)$ & 70 (49-93) & 0.627 \\
\hline Positive RF, $n(\%)$ & $49(86)$ & $10(91)$ & $39(85)$ & 0.599 \\
\hline Positive ACPA, $n(\%)$ & $52(91)$ & $11(100)$ & $41(89)$ & 0.252 \\
\hline DAS28-CRP & $5.3(4.6-6.1)$ & $4.7(4.2-5.8)$ & $5.6(5.0-6.3)$ & 0.024 \\
\hline DAS28-ESR & $6.2(5.4-7.0)$ & $5.4(4.7-6.2)$ & $6.4(5.6-7.0)$ & 0.019 \\
\hline SDAl & $31.8(21.8-42.3)$ & $22.1(17.5-34.2)$ & $33.0(26.9-43.7)$ & 0.026 \\
\hline CDAl & $27(19-39)$ & $19(10-27)$ & $30(22-41)$ & 0.009 \\
\hline RAPID3 & $12.7(8.8-14.8)$ & $7.1(5.5-12.4)$ & $13.1(10.6-15.1)$ & 0.001 \\
\hline HAQ-DI & $1.3(0.6-1.9)$ & $0.5(0.1-1.4)$ & $1.4(0.9-2.0)$ & 0.014 \\
\hline \multicolumn{5}{|l|}{ Liver function } \\
\hline AST, U/L & $16(14-23)$ & $22(17-28)$ & $16(14-18)$ & 0.027 \\
\hline $\mathrm{ALT}, \mathrm{U} / \mathrm{L}$ & $15(11-21)$ & $19(14-31)$ & $15(11-19)$ & 0.087 \\
\hline \multicolumn{5}{|l|}{ Radiographic status } \\
\hline Bony erosions, $n(\%)$ & $48(84)$ & $9(82)$ & $39(85)$ & 0.809 \\
\hline JSN subscore & $4(0-17)$ & $1(0-11)$ & $5(1-18)$ & 0.331 \\
\hline JE subscore & $7(2-20)$ & $2(1-23)$ & $9(2-19)$ & 0.447 \\
\hline mTSS & $12(4-34)$ & $9(1-34)$ & $13(4-35)$ & 0.352 \\
\hline \multicolumn{5}{|c|}{ Previous medications, $n$ (\%) } \\
\hline Treatment-naïve $^{b}$ & $35(61)$ & $5(46)$ & $30(65)$ & 0.226 \\
\hline Glucocorticosteroids & $21(37)$ & $4(36)$ & $17(37)$ & 0.971 \\
\hline Methotrexate & $10(18)$ & $3(27)$ & $7(15)$ & 0.345 \\
\hline Leflunomide & $10(18)$ & 0 & $10(22)$ & NA \\
\hline Sulfasalazine & $6(11)$ & $2(18)$ & $4(9)$ & 0.357 \\
\hline Hydroxychloroquine & $5(9)$ & $3(27)$ & $2(4)$ & 0.016 \\
\hline Biologic DMARDs & $1(2)$ & 0 & $1(2)$ & NA \\
\hline \multicolumn{5}{|l|}{ Initial medications, n (\%) } \\
\hline Glucocorticosteroids & $44(77)$ & $8(73)$ & $36(78)$ & 0.694 \\
\hline Methotrexate & $54(95)$ & $10(91)$ & $44(96)$ & 0.527 \\
\hline Leflunomide & $39(68)$ & 0 & $39(85)$ & $<0.001$ \\
\hline Sulfasalazine & $10(18)$ & $9(82)$ & $1(2)$ & $<0.001$ \\
\hline Hydroxychloroquine & $12(21)$ & $10(91)$ & $2(4)$ & $<0.001$ \\
\hline
\end{tabular}


Table 1 Baseline characteristics of patients (Continued)

\begin{tabular}{llll}
\hline Parameters & $\begin{array}{l}\text { All patients } \\
(n=57)\end{array}$ & $\begin{array}{l}\text { CHB group } \\
(n=11)\end{array}$ & $\begin{array}{l}\text { Non-CHB group } \\
(n=46)\end{array}$ \\
\hline Biologic DMARDs & $25(44)$ & $3(27)$ & $22(48)$
\end{tabular}

Abbreviations: ACPA Anti-cyclic citrullinated peptide antibody, ALT Alanine aminotransferase, AST Aspartate transaminase, CDAI Clinical Disease Activity Index, CHB Chronic hepatitis B virus infection, CRP C-reactive protein, DAS28 Disease Activity Score 28-joint assessment, DMARD Disease-modifying anti-rheumatic drug, ESR Erythrocyte sedimentation rate, HAQ-DI Stanford Health Assessment Questionnaire Disability Index, JE Joint erosion, JSN Joint space narrowing, mTSS Modified total Sharp score, NA Not applicable, Pain VAS Pain visual analogue scale, PrGA Provider global assessment of disease activity, PtGA Patient global assessment of disease activity, RA Rheumatoid arthritis, RAPID3 Routine Assessment of Patient Index Data 3, RF Rheumatoid factor, SDAI Simplified Disease Activity Index, SJC28 28-joint swollen joint count, TJC28 28-joint tender joint count

${ }^{a}$ Comparison between the CHB and non-CHB groups. Data correspond to number (percent) or median (interquartile range) unless stated otherwise. Bold $p$ values indicate statistically significant levels

${ }^{\mathrm{b}}$ Without glucocorticosteroid or disease-modifying anti-rheumatic drug therapy in the 6 months before entry into the study

activity indicators between the resolved HBV group and the non-HBV group.

Spearman's rank-order correlation test was used to assess the relationship between baseline serum HBV DNA levels and clinical outcomes in the $\mathrm{CHB}$ group. The results revealed positive correlations between HBV DNA titers and RAPID3 at month $1(r=0.671, p=0.024)$ and month $3(r=0.713, p=0.014)$. Significant correlations were also observed between a level of HBV DNA $\geq$ $10^{4} \mathrm{IU} / \mathrm{ml}$ and PtGA at month $12(r=0.645, p=0.032)$,
SDAI at month $6(r=0.635, p=0.036)$, and RAPID3 at month $1(r=0.637, p=0.035)$, month $6(r=0.637, p=$ $0.035)$, and month $12(r=0.638, p=0.035)$.

\section{Radiographic progression}

No significant difference was found in JE subscore, JSN subscore, or mTSS between the $\mathrm{CHB}$ and non- $\mathrm{CHB}$ groups at baseline (all $p>0.05$ ) (Table 1). Thirty-three percent of patients with RA had 1-year radiographic progression. Compared with the non- $\mathrm{CHB}$ group, a

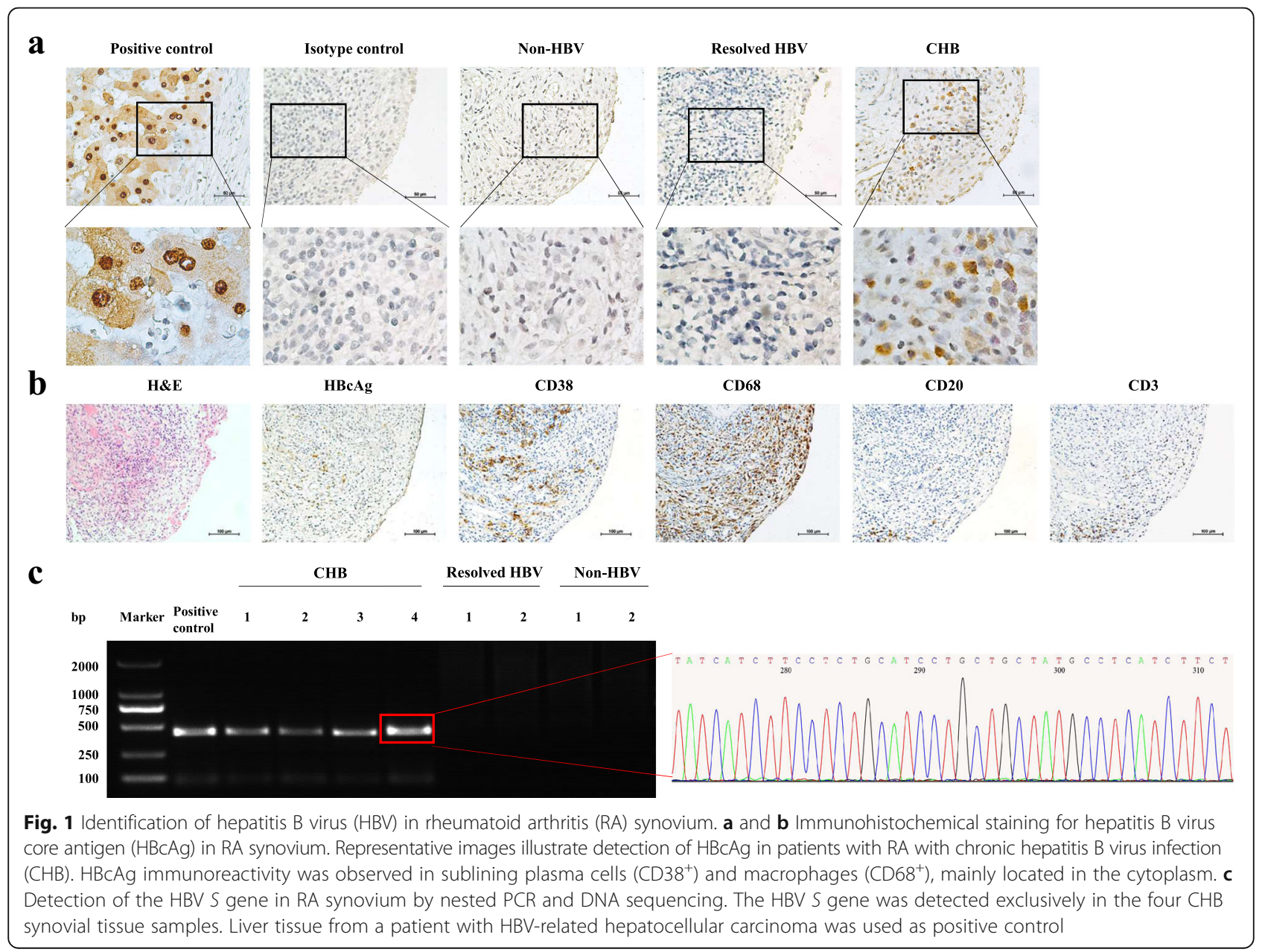


Table 2 Comparison of synovial histopathological features

\begin{tabular}{|c|c|c|c|c|c|c|}
\hline Parameters & $\begin{array}{l}\text { CHB group } \\
(n=11)\end{array}$ & $\begin{array}{l}\text { Non-CHB group } \\
(n=46)\end{array}$ & $p$ Value $^{\mathrm{b}}$ & $\begin{array}{l}\mathrm{HBCAg}(+)^{C} \\
(n=7)\end{array}$ & $\begin{array}{l}\operatorname{HBCAg}(-)^{c} \\
(n=4)\end{array}$ & $p$ Value \\
\hline$\overline{\mathrm{MVCs}}, / \mathrm{mm}^{2}$ & $145(102-216)$ & $140(118-177)$ & 0.473 & $133-286$ & $93-145$ & 0.023 \\
\hline $\mathrm{CD}^{+} \mathrm{T}$ cells, $/ \mathrm{mm}^{2}$ & $1141(560-1751)$ & $639(473-1131)$ & 0.124 & $0-2103$ & $425-1934$ & 0.571 \\
\hline $\mathrm{CD} 15^{+}$neutrophils, $/ \mathrm{mm}^{2}$ & $638(297-897)$ & $229(149-389)$ & 0.010 & $63-1367$ & $16-1484$ & 0.850 \\
\hline $\mathrm{CD} 20^{+} \mathrm{B}$ cells, $/ \mathrm{mm}^{2}$ & $1216(472-2834)$ & $340(122-753)$ & 0.001 & $773-4695$ & $267-1940$ & 0.038 \\
\hline $\mathrm{CD} 8^{+}$plasma cells, $/ \mathrm{mm}^{2}$ & $1594(380-2223)$ & 815 (269-1346) & 0.124 & $519-4486$ & 120-1795 & 0.059 \\
\hline $\mathrm{CD}^{+} 8^{+}$macrophages ${ }^{\mathrm{e}}, / \mathrm{mm}^{2}$ & $1873(1016-2304)$ & $923(622-1310)$ & $<0.001$ & $1016-2806$ & $968-2826$ & 0.257 \\
\hline Sublining $\mathrm{CD} 8^{+}$macrophages & $1686(871-2075)$ & $659(449-1005)$ & $<0.001$ & $991-2496$ & $784-1345$ & 0.023 \\
\hline Lining $\mathrm{CD} 8^{+}$macrophages & $202(158-238)$ & $212(126-266)$ & 0.911 & $158-330$ & $193-480$ & 0.450 \\
\hline Krenn synovitis score & $4(2-7)$ & $5(4-6)$ & 0.682 & $2-7$ & $1-4$ & 0.071 \\
\hline Hyperplasia of lining layer & $2(1-2)$ & $2(1-2)$ & 0.808 & $1-3$ & $1-2$ & 0.308 \\
\hline Inflammatory infiltration & $1(1-2)$ & $1(1-2)$ & 0.514 & $0-3$ & $0-1$ & 0.072 \\
\hline Synovial stroma activation & $1(1-2)$ & $2(1-2)$ & 0.278 & $1-3$ & $0-1$ & 0.025 \\
\hline
\end{tabular}

Abbreviations: CHB Chronic HBV infection, HBCAg Hepatitis B virus core antigen, MVC Microvessel count, RA Rheumatoid arthritis

${ }^{a}$ Data correspond to median (interquartile range) unless stated otherwise. Bold $p$ values indicate statistically significant levels

${ }^{b}$ Comparison between the $\mathrm{CHB}$ and non-CHB groups

'Data correspond to minimum - maximum

${ }^{d}$ Comparison of HBcAg-positive vs. HBcAg-negative synovial specimens from patients with $\mathrm{CHB}$

${ }^{e} \mathrm{CD} 68$-positive macrophages included lining and sublining CD68-positive macrophages

significantly higher percentage of patients with RA with CHB experienced 1-year radiographic progression (64\% vs. $26 \%, p=0.024)$, together with greater increases in JE subscore (1.5 [IQR $0-4.0]$ vs. 0 [IQR $0-0], p=0.024)$ and mTSS (1.5 [IQR 0-4.0] vs. 0 [IQR 0-0.9], $p=0.024)$. The cumulative probability distribution of radiographic change in mTSS from baseline to month 12 for patients with RA in the $\mathrm{CHB}$ and non-CHB groups is shown in Fig. 3, where the space between the curves indicates that a higher percentage of patients with RA with $\mathrm{CHB}$ experienced 1 -year radiographic progression. There were no significant differences in all these indicators between the resolved HBV group and the non-HBV group (all $p>0.05$ ).

Spearman's rank-order correlation test was used to assess the relationship between baseline serum HBV DNA levels and radiographic outcomes in the $\mathrm{CHB}$ group. The results revealed positive correlations between HBV DNA titers and increases in JSN subscore $(r=0.606, p=0.048)$ and rapid radiographic progression $(r=0.677, p=0.022)$.

\section{Risk factors for 1-year radiographic progression}

To determine risk factors for 1-year radiographic progression, univariate logistic regression analysis was performed, including baseline characteristics and initial therapies after enrollment as variables. The results showed that $\mathrm{CHB}$ status, female sex, smoking status, and treatment-naive status as well as higher baseline mTSS were significantly associated with 1 -year radiographic progression (all $p<0.05$ ) (Table 3). In bivariate analyses that were adjusted for the significant confounding factors in univariate logistic regression analysis, $\mathrm{CHB}$ status was always positively associated with 1-year radiographic progression (OR 4.632-7.069, all $p<0.05$ ). Furthermore, multivariate logistic regression analysis that was adjusted for all significant factors in univariate analyses revealed that CHB status (OR 14.230, 95\% CI 2.213-95.388, $p=0.006)$ and the count of CD68-positive macrophages (OR 1.002, 95\% CI 1.001-1.003, $p=0.003$ ) were independently associated with 1 -year radiographic progression.

\section{Discussion}

This study was performed using a prospective cohort of consecutive patients with RA with available synovium. The results of immunohistochemical staining and nested PCR revealed the presence of $\mathrm{HBcAg}$ and HBV $S$ gene in the synovium from patients with RA with $\mathrm{CHB}$. Of note, this is the first report, to our knowledge, of the presence of HBV in RA synovium. Synovial tissue is the primary target of disturbed immunomodulatory pathways in RA. Our previous study revealed HBV DNA in synovial fluid from patients with RA with $\mathrm{CHB}$, but it failed to demonstrate positive HBsAg staining by immunohistochemistry in the synovium from patients with RA with either current or resolved HBV infection [7]. In the present study, even though results of HBsAg staining were negative using two different commercial antibodies against HBsAg, HBV was detected in the synovium of patients with RA with $\mathrm{CHB}$, as evidenced by positive $\mathrm{HBcAg}$ immunoreactivity and further confirmation by nested PCR for the HBV $S$ gene. $\mathrm{HBcAg}$ is a reliable marker for $\mathrm{HBV}$ infection and viral replication. Full-length $\mathrm{HBc}$ capsids could induce tumor necrosis factor- $\alpha$ (TNF- $\alpha$ ), interleukin (IL)-6, and IL-12p40 via 

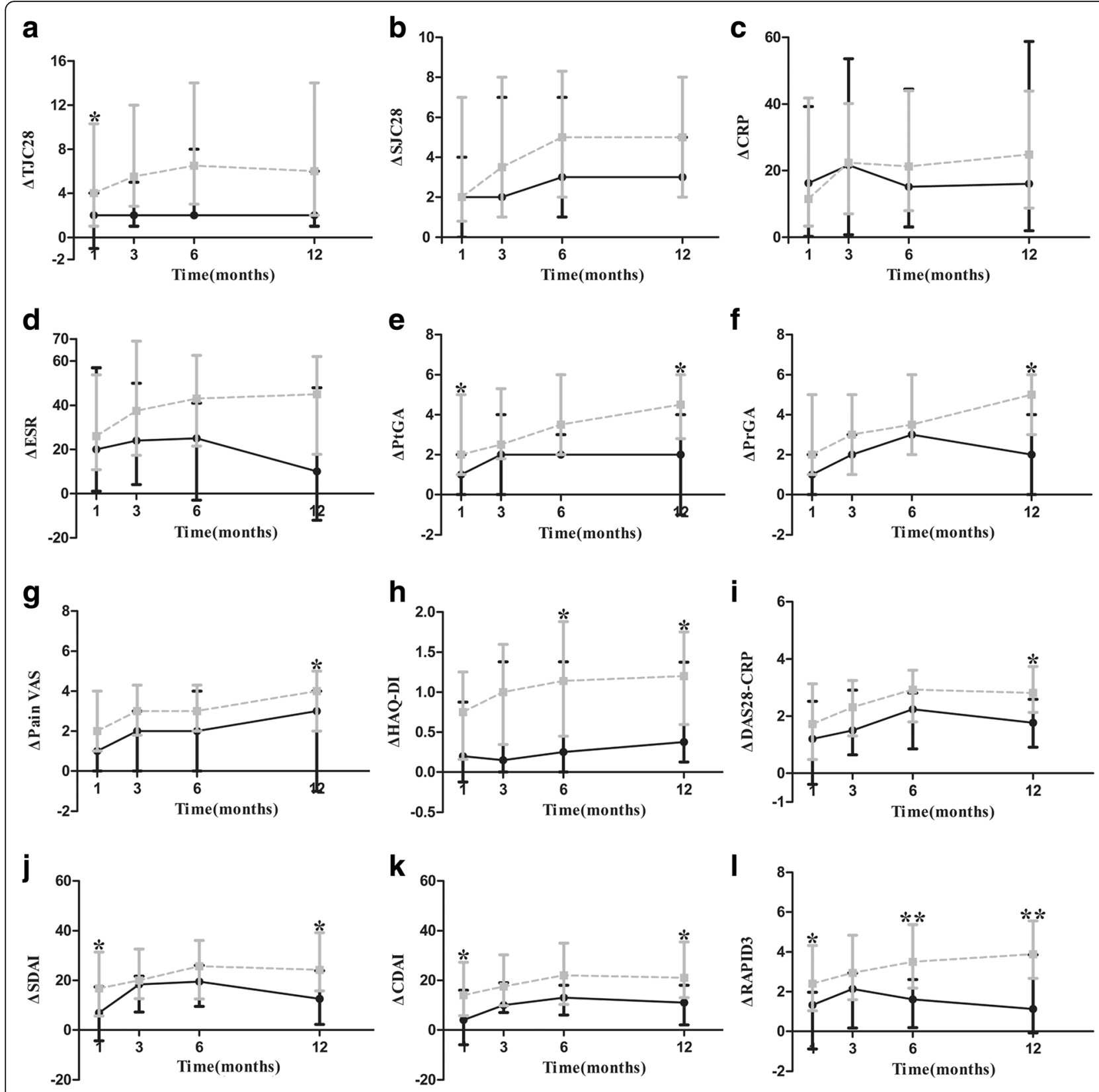

CHB group

-늘- Non-CHB group

Fig. 2 Comparison of improvements in disease activity indicators between patients with rheumatoid arthritis (RA) with and without chronic hepatitis B virus infection (CHB). a-I Compared with the non-CHB group, patients with RA in the CHB group experienced significantly smaller improvements from baseline in most disease activity indicators mainly at month 12 (including PtGA, PrGA, Pain VAS, HAQ-DI, DAS28-CRP, SDAl, and (DAI), in TJC28 at month 1, and especially RAPID3 at almost each point except month 3, but no significant improvements were observed in SJC28, CRP, or ESR. ${ }^{*} p<0.05,{ }^{* *} p<0.01$. CDAl Clinical Disease Activity Index, CRP C-reactive protein, DAS28 Disease Activity Score 28-joint assessment, ESR Erythrocyte sedimentation rate, HAQ-DI Stanford Health Assessment Questionnaire Disability Index, Pain VAS Pain visual analogue scale, PrGA Provider global assessment of disease activity, PtGA Patient global assessment of disease activity, RAPID3 Routine Assessment of Patient Index Data 3, SDAI Simplified disease activity index, SJC28 28-joint swollen joint count, TJC28 28-joint tender joint count

activation of nuclear factor kappa-B (NF-kB), extracellular signal-regulated protein kinases $1 / 2$, and p38 mitogen-activated protein kinase in macrophages [28]. The distribution of HBcAg could be generally classified as cytoplasmic, nuclear, or mixed in expression [29]. Cytoplasmic HBcAg is more likely to be recognized by $\mathrm{CD} 4^{+} \mathrm{T}$ cells and acts as a target antigen of immune-mediated cytolysis, which implicates its role in 

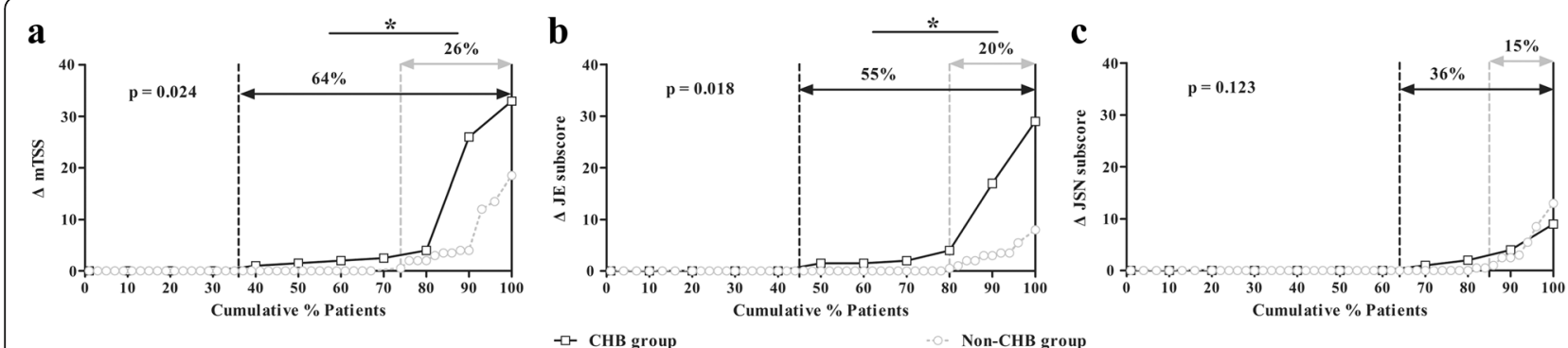

Fig. 3 One-year radiographic changes of patients with rheumatoid arthritis (RA) with and without chronic hepatitis B virus infection (CHB). Comparison of cumulative probability of $\triangle \mathrm{mTSS}(\mathbf{a}), \triangle \mathrm{JE}$ subscore (b), and $\triangle \mathrm{SSN}$ subscore (c) during 1-year follow-up between patients with RA with and without CHB. Cumulative probability distribution of radiographic change in mTSS from baseline to month 12 demonstrated that a significantly higher percentage of patients with CHB displayed 1-year radiographic progression. ${ }^{*} p<0.05$. JE Joint erosion; JSN Joint space narrowing; mTSS Modified total Sharp score

the pathogenesis of liver damage caused by HBV infection [30, 31]. HBV DNA replicative intermediates and viral proteins can be detected in peripheral blood mononuclear cells (PBMCs) of patients with $\mathrm{CHB}$, with monocytes and B cells being the most frequently infected cells [32]. Studies on vertical transmission revealed the presence of $\mathrm{HBsAg}$ and $\mathrm{HBcAg}$ in $\mathrm{CD}^{+} 8^{+}$cells of villous stroma and blood capillaries in placenta from mothers with HBV-positive PBMCs, which may serve as a vector for maternal-fetal transmission of HBV [33]. In our study, $\mathrm{HBcAg}$ was located mainly in the cytoplasm of plasma cells and sublining macrophages in the synovium, which may result partially from migration and differentiation of HBV-infected PBMCs. However, studies have suggested that the severity of extrahepatic disease in patients with HBV infection might be related to viral burden, which may need to reach a certain threshold before extrahepatic HBV syndromes become clinically evident $[5,34]$. In this study, higher baseline serum HBV DNA levels were observed to be positively correlated with poorer clinical and radiographic outcomes, indicating that higher levels of HBV DNA may contribute to more pronounced disease progression. However, our results showed that not all patients with RA with $\mathrm{CHB}$ had HBV markers in the synovium and that the intensity of $\mathrm{HBcAg}$ expression was not completely in line with serum HBV DNA level. Owing to confounding factors such as different antiviral therapies and anti-RA regimens among different patients, it may not suffice to simply investigate the relationship between serum HBV DNA levels and RA clinical characteristics. Future studies should feature larger numbers of patients with RA with $\mathrm{CHB}$ and thus provide sufficient statistical power for further multivariate logistic regression analyses.

Further analyses of the influence of HBV infection on histopathological characteristics of synovitis showed more pronounced CD68-positive macrophages, CD20-positive $B$ cells, and CD15-positive neutrophils infiltrating CHB synovium. Despite the small number of $\mathrm{CHB}$ specimens, this group seemed to have a higher synovial stroma activation subscore, more MVCs, and more pronounced sublining CD68-positive macrophages as well as CD20-positive $B$ cells in CHB synovium with positive HBcAg than without it. Synovial macrophages are the main source of proinflammatory cytokines, including TNF- $\alpha$ and IL-1. Their density (cell count per unit area) is associated with synovial inflammation and joint destruction in RA, and it has a predictive role in evaluating the clinical efficacy of RA treatment [35]. Increased CD20-positive B cells infiltrating RA synovium could promote disease progression by producing autoantibodies and cytokines such as TNF- $\alpha$, IL-6, and receptor activator of NF- $\mathrm{kB}$ ligand [36], enhancing osteoclastogenesis. B-cell-targeted therapy such as rituximab can alleviate such abnormalities and improve disease prognosis. Neutrophils have been a focus of RA research since the discovery of neutrophil extracellular traps (NETs), and increased components of NETs have been found in RA sera [37]. NETs are highly enriched in specific autoantigens such as citrullinated proteins targeted by ACPA in patients with RA [38, 39], but they also provide stimuli to fibroblast-like synoviocytes [40], dendritic cells [41], macrophages [42], and lymphocytes [43, 44], which promote systemic and local (synovial) autoimmune responses. However, although no significant difference was found in $\mathrm{CD}^{+} \mathrm{T}$-cell count between $\mathrm{CHB}$ synovium with and without positive $\mathrm{HBcAg}$, there was a trend of more $\mathrm{CD}^{+} \mathrm{T}$ cells infiltrating $\mathrm{CHB}$ synovium than non-CHB synovium $\left(1141\right.$ [560-1751]/ $\mathrm{mm}^{2}$ vs. 639 [473$\left.1131] / \mathrm{mm}^{2}, p=0.124\right)$. The small number of RA synovial tissues may have precluded us from obtaining a statistically significant difference. In the present study, we only used CD3 to stain for T cells in RA synovium. Therefore, we cannot rule out the possibility of an increased count or an enhanced activity of some T-cell subsets in the CHB synovium. Further explorations on the topic and the potential mechanism are needed. In total, HBV infection-especially its presence in synovium-may play a role in the pathogenesis of local lesions of synovitis in RA. 
Table 3 Logistic regression analyses for risk factors of 1-year radiographic progression

\begin{tabular}{|c|c|c|c|}
\hline Parameters & OR & $95 \% \mathrm{Cl}$ & $p$ Value $^{\mathrm{a}}$ \\
\hline \multicolumn{4}{|l|}{ Univariate analyses } \\
\hline Female & 0.258 & $(0.073-0.910)$ & 0.035 \\
\hline Age & 0.965 & $(0.922-1.010)$ & 0.128 \\
\hline Disease duration & 1.008 & $(1.000-1.017)$ & 0.050 \\
\hline Smoking status & 3.850 & $(1.024-14.473)$ & 0.046 \\
\hline CHB status & 4.958 & $(1.231-19.980)$ & 0.024 \\
\hline TJC28 & 0.958 & $(0.885-1.126)$ & 0.293 \\
\hline SJC28 & 1.017 & $(0.918-1.126)$ & 0.752 \\
\hline PtGA & 1.122 & $(0.853-1.476)$ & 0.411 \\
\hline $\operatorname{PrGA}$ & 1.031 & $(0.766-1.387)$ & 0.841 \\
\hline Pain VAS & 1.093 & $(0.824-1.448)$ & 0.537 \\
\hline CRP & 1.008 & $(0.991-1.025)$ & 0.342 \\
\hline ESR & 0.993 & $(0.997-1.010)$ & 0.441 \\
\hline Positive RF & 4.065 & $(0.462-35.752)$ & 0.206 \\
\hline Positive ACPA & 0.729 & $(0.111-4.778)$ & 0.741 \\
\hline DAS28-CRP & 0.975 & $(0.571-1.664)$ & 0.926 \\
\hline HAQ-DI & 0.724 & $(0.359-1.463)$ & 0.369 \\
\hline mTSS & 1.024 & $(1.004-1.044)$ & 0.021 \\
\hline Treatment-naïve ${ }^{b}$ & 0.296 & $(0.094-0.935)$ & 0.038 \\
\hline Glucocorticosteroids ${ }^{c}$ & 1.164 & $(0.307-4.412)$ & 0.823 \\
\hline Methotrexate $e^{c f}$ & 1.000 & $(0.085-11.778)$ & 0.999 \\
\hline Leflunomide ${ }^{c}$ & 0.397 & $(0.125-1.259)$ & 0.117 \\
\hline Sulfasalazine ${ }^{c}$ & 1.905 & $(0.497-7.294)$ & 0.347 \\
\hline Hydroxychloroquine ${ }^{c}$ & 3.111 & $(0.868-11.149)$ & 0.081 \\
\hline Biological DMARDs ${ }^{c}$ & 0.357 & $(0.107-1.189)$ & 0.093 \\
\hline MVCs & 1.005 & $(0.996-1.014)$ & 0.302 \\
\hline CD3-positive T cells ${ }^{d}$ & 1.000 & $(0.999-1.001)$ & 0.982 \\
\hline $\begin{array}{l}\text { CD15-positive } \\
\text { neutrophils }\end{array}$ & 1.001 & $(0.999-1.002)$ & 0.393 \\
\hline $\begin{array}{l}\text { CD20-positive B } \\
\text { cells }^{\mathrm{e}}\end{array}$ & 1.000 & $(1.000-1.001)$ & 0.389 \\
\hline $\begin{array}{l}\text { CD38-positive plasma } \\
\text { cells }^{f}\end{array}$ & 1.000 & $(1.000-1.001)$ & 0.396 \\
\hline $\begin{array}{l}\text { CD68-positive } \\
\text { macrophages }\end{array}$ & 1.002 & $(1.000-1.003)$ & 0.006 \\
\hline \multicolumn{4}{|l|}{ Bivariate models } \\
\hline $\begin{array}{l}\text { CHB status adjusted } \\
\text { for gender }\end{array}$ & 4.632 & $(1.089-19.697)$ & 0.038 \\
\hline $\begin{array}{l}\text { CHB status adjusted } \\
\text { for smoking status }\end{array}$ & 6.097 & $(1.397-26.616)$ & 0.016 \\
\hline $\begin{array}{l}\text { CHB status adjusted } \\
\text { for treatment-naïve } \\
\text { status }\end{array}$ & 4.958 & $(1.231-19.980)$ & 0.024 \\
\hline $\begin{array}{l}\text { CHB status adjusted } \\
\text { for baseline mTSS }\end{array}$ & 7.069 & $(1.539-32.480)$ & 0.012 \\
\hline
\end{tabular}

Table 3 Logistic regression analyses for risk factors of 1-year radiographic progression (Continued)

\begin{tabular}{|c|c|c|c|}
\hline Parameters & OR & $95 \% \mathrm{Cl}$ & $p$ Value $^{a}$ \\
\hline \multicolumn{4}{|l|}{ Multivariate models ${ }^{g}$} \\
\hline $\begin{array}{l}\text { CHB status adjusted for } \\
\text { gender, smoking status, } \\
\text { treatment-naïve status, } \\
\text { and baseline mTSS }\end{array}$ & 14.230 & $(2.123-95.388)$ & 0.006 \\
\hline $\begin{array}{l}\text { CD68-positive macrophages } \\
\text { adjusted for gender, smoking } \\
\text { status, treatment-naïve status, } \\
\text { and baseline mTSS }\end{array}$ & 1.002 & $(1.001-1.003)$ & 0.003 \\
\hline
\end{tabular}

Abbreviations: ACPA Anti-cyclic citrullinated peptide antibody, $\mathrm{CHB}$ Chronic hepatitis $B$ virus infection, CRP C-reactive protein, DAS28 Disease Activity Score 28-joint assessment, ESR Erythrocyte sedimentation rate, HAQ-DI Stanford Health Assessment Questionnaire Disability Index, mTSS Modified total Sharp score, MVC Microvessel count, Pain VAS Pain visual analogue scale, PrGA Provider global assessment of disease activity, PtGA Patient global assessment of disease activity, RA Rheumatoid arthritis, RF Rheumatoid factor, SJC28 28joint swollen joint count, $T J C 28$ 28-joint tender joint count

${ }^{a}$ Calculated using logistic regression analysis. Bold $p$ values indicate statistically significant levels

${ }^{b}$ Without glucocorticosteroid or disease-modifying anti-rheumatic drug therapy since 6 months before enrollment

I Initial medications after enrollment

${ }^{\text {E} M e t h o t r e x a t e: ~ O R: ~ 1.000000, ~ 95 \% ~ C l: ~ 0.084904-11.778006, ~} p=0.999$

${ }^{\mathrm{d}} \mathrm{CD} 3$-positive T cells: OR: $1.000011,95 \% \mathrm{Cl}$ : 0.999047-1.000976, $p=0.982$

${ }^{\mathrm{e}} \mathrm{CD} 20$-positive B cells: OR: $1.000272,95 \% \mathrm{Cl}: 0.999653-1.000892, p=0.389$

${ }^{f} \mathrm{CD} 38$-positive plasma cells: OR: $1.000261,95 \% \mathrm{Cl}$ :

$0.999658-1.000865, p=0.396$

${ }^{9}$ Owing to the multicollinearity between $\mathrm{CHB}$ status and the total count of CD68-positive macrophages, two multivariate models were established,

respectively, by adjusting for all significant univariate factors

Previous studies have indicated that HBV infection was more likely to be an exacerbating factor in the pathogenicity and progression of RA. Arthritis of several patients with HBV infection who fulfilled the ACR diagnostic criteria for RA could be resolved by anti-HBV therapy $[45,46]$. An acute case of seropositive RA was reported in a woman 24 hours after receiving the first dose of hepatitis B vaccine. She showed a steady improvement after receiving glucocorticosteroids and sulfasalazine, but $\mathrm{x}$-rays of both hands showed erosions with minimal periarticular osteoporosis 10 months later [47]. In the present study, analysis of the influence of HBV infection on clinical and radiographic outcomes showed smaller improvements from baseline in most disease activity indicators at month 12 , with a significantly higher percentage of patients with $\mathrm{CHB}$ experiencing 1-year radiographic progression, and multivariate logistic regression analysis revealed that $\mathrm{CHB}$ status was an independent risk factor for 1-year radiographic progression in RA. These results were consistent with the aforementioned hypothesis and further implied that HBV infection might exacerbate disease progression, causing poor clinical response and subsequent radiographic progression in patients with RA with $\mathrm{CHB}$. With the results of histopathological characteristics of synovitis, we speculated that RA concurrent with $\mathrm{HBV}$ infection, especially 
its presence in synovium, may be classified as a new phenotype of HBV-induced RA that may need adjusted and specific treatment regimens to obtain a satisfactory therapeutic response.

There are several limitations of this study. First, the small number of patients with RA with $\mathrm{CHB}$ and synovial tissue of adequate quality clearly limits its statistical power. There was no significant difference in disease activity or 1-year radiographic progression between patients with $\mathrm{CHB}$ with and without $\mathrm{HBcAg}$ expression in synovium. Despite the small number of $\mathrm{CHB}$ synovial samples, patients with positive $\mathrm{HBcAg}$ in synovium seemed to have more pronounced synovitis than those without it. Second, compared with the non-CHB group, a tendency of longer disease duration (120 [6-120] vs. 24 [7-72], $p=0.345)$ and a smaller percentage of medication-naïve patients ( $46 \%$ vs. $65 \%, p=0.226$ ) were observed in the CHB group, which may lead to significantly lower levels of most disease activity indicators at baseline and subsequent analyses at each visit. Further prospective cohort studies of RA with more patients with $\mathrm{CHB}$, especially treatment-naïve patients with early disease, are needed. The potential mechanism of HBV infection in RA progression, the possibility of a new phenotype of HBV-induced RA, and the method of choosing DMARDs and antiviral therapy for these patients merit further exploration.

\section{Conclusions}

This study reveals the presence of HBV in the synovium of patients with RA with CHB. HBV may be involved in the pathogenesis of local lesions and exacerbate disease progression, including disease activity and joint destruction.

\section{Additional file}

Additional file 1: Dynamic disease activity indicators in all patients with RA during 1-year follow-up ${ }^{+}$. (PDF $71 \mathrm{~kb}$ )

\section{Acknowledgements}

The authors thank the patients and medical staff for their contributions to the study and Yan-Fang Ye of Sun Yat-Sen Memorial Hospital for her statistical assistance. This paper is dedicated to the memory of Prof. H. Ralph Schumacher Jr., pioneer of the closed-needle synovial biopsy technique.

\section{Funding}

This work was supported by the National Natural Science Foundation of China (nos. 81471597, 81671612, and 81601427), Guangdong Natural Science Foundation (nos. 2016A030313307, 2017A030313576, and 2017A030310236), and Fundamental Research Funds for the Central Universities (no. 17ykjc12).

Availability of data and materials

The datasets used and/or analyzed during the present study are available from the corresponding author on reasonable request.

\section{Authors' contributions}

YLC conceived of and designed the study, analyzed the data, and drafted the manuscript. LD and FP conceived of and participated in the study, read and analyzed documents, and revised the manuscript. JJ, YQM, LJY, and DHZ participated in clinical assessment at each visit during the follow-up. LFC and TY performed synovitis assessments and cell counting. JDM and XZ performed the radiographic assessment. All authors contributed to the final manuscript. All authors read and approved the final manuscript.

\section{Ethics approval and consent to participate}

All participants gave their written informed consent before clinical data collection. This study was conducted in compliance with the Helsinki declaration and was approved by the Medical Ethics Committee of Sun Yat-Sen Memorial Hospital (identifier SYSEC-2009-06).

\section{Consent for publication}

All participants approved of publishing the data in this paper.

\section{Competing interests}

The authors declare that they have no competing interests relating to the conduct of the study or the publication of this report.

\section{Publisher's Note}

Springer Nature remains neutral with regard to jurisdictional claims in published maps and institutional affiliations.

\section{Author details}

'Department of Rheumatology, Sun Yat-Sen Memorial Hospital, Sun Yat-Sen University, Guangzhou, People's Republic of China. ${ }^{2}$ Department of Radiology, Sun Yat-Sen Memorial Hospital, Sun Yat-Sen University, Guangzhou, People's Republic of China. 'Zhongshan School of Medicine, Sun Yat-sen University, Guangzhou, People's Republic of China. ${ }^{4}$ TWINCORE Center for Experimental and Clinical Infection Research, Hannover, Germany. ${ }^{5}$ Helmholtz Center for Infection Research, Braunschweig, Germany.

Received: 16 March 2018 Accepted: 14 May 2018 Published online: 19 June 2018

\section{References}

1. Mclnnes IB, Schett G. Pathogenetic insights from the treatment of rheumatoid arthritis. Lancet. 2017;389:2328-37.

2. Ebringer A, Wilson C. HLA molecules, bacteria and autoimmunity. J Med Microbiol. 2000;49:305-11.

3. Alam J, Jantan I, Bukhari SNA. Rheumatoid arthritis: recent advances on its etiology, role of cytokines and pharmacotherapy. Biomed Pharmacother. 2017:92:615-33.

4. Neuveut C, Yu W, Buendia MA. Mechanisms of HBV-related hepatocarcinogenesis. J Hepatol. 2010;52:594-604.

5. Mason A, Theal J, Bain V, Adams E, Perrillo R. Hepatitis B virus replication in damaged endothelial tissues of patients with extrahepatic disease. Am J Gastroenterol. 2005:100:972-6.

6. Pope JE, Stevens A, Howson W, Bell DA. The development of rheumatoid arthritis after recombinant hepatitis B vaccination. J Rheumatol. 1998;25: $1687-93$. 
7. Zou CJ, Zhu LJ, Li YH, Mo YQ, Zheng DH, Ma JD, et al. The association between hepatitis B virus infection and disease activity, synovitis, or joint destruction in rheumatoid arthritis. Clin Rheumatol. 2013;32:787-95.

8. Hsu CS, Lang HC, Huang KY, Lin HH, Chen CL. Association of rheumatoid arthritis and hepatitis B infection: a nationwide nested case-control study from 1999 to 2009 in Taiwan. Medicine (Baltimore). 2016;95:e3551.

9. Schumacher HR, Gall EP. Arthritis in acute hepatitis and chronic active hepatitis: pathology of the synovial membrane with evidence for the presence of Australia antigen in synovial membranes. Am J Med. 1974:57:655-64.

10. Momohara S, Okamoto H, Tokita N, Tomatsu T, Kamatani N. Rapidly destructive knee arthropathy associated with hepatitis B. Clin Exp Rheumatol. 2006;24:111-2.

11. Arnett FC, Edworthy SM, Bloch DA, McShane DJ, Fries JF, Cooper NS, et al. The American Rheumatism Association 1987 revised criteria for the classification of rheumatoid arthritis. Arthritis Rheum. 1988;31:315-24.

12. Aletaha D, Neogi T, Silman AJ, Funovits J, Felson DT, Bingham CR, et al. 2010 Rheumatoid arthritis classification criteria: an American College of Rheumatology/European League Against Rheumatism collaborative initiative. Ann Rheum Dis. 2010;69:1580-8.

13. Hou JL, Lai W. The guideline of prevention and treatment for chronic hepatitis B: a 2015 update. Zhonghua Gan Zang Bing Za Zhi. 2015;23:888-905.

14. Radner H, Chatzidionysiou K, Nikiphorou E, Gossec L, Hyrich KL, Zabalan C, et al. 2017 EULAR recommendations for a core data set to support observational research and clinical care in rheumatoid arthritis. Ann Rheum Dis. 2018;77:476-9.

15. Ma J, Wei X, Zheng D, Mo Y, Chen L, Zhang X, et al. Continuously elevated serum matrix metalloproteinase-3 for $3 \sim 6$ months predict one-year radiographic progression in rheumatoid arthritis: a prospective cohort study. Arthritis Res Ther. 2015;17:289.

16. van der Heijde D, van der Helm-van MA, Aletaha D, Bingham CO, Burmester $G R$, Dougados $M$, et al. EULAR definition of erosive disease in light of the 2010 ACR/EULAR rheumatoid arthritis classification criteria. Ann Rheum Dis. 2013;72:479-81.

17. Takeuchi T, Yamanaka H, Ishiguro N, Miyasaka N, Mukai M, Matsubara T, et al. Adalimumab, a human anti-TNF monoclonal antibody, outcome study for the prevention of joint damage in Japanese patients with early rheumatoid arthritis: the HOPEFUL 1 study. Ann Rheum Dis. 2014;73:536-43.

18. Meyer M, Sellam J, Fellahi S, Kotti S, Bastard JP, Meyer O, et al. Serum level of adiponectin is a surrogate independent biomarker of radiographic disease progression in early rheumatoid arthritis: results from the ESPOIR cohort. Arthritis Res Ther. 2013;15:R210.

19. Schumacher HJ, Kulka JP. Needle biopsy of the synovial membrane-experience with the Parker-Pearson technic. N Engl J Med. 1972:286:416-9.

20. Ma JD, Zhou JJ, Zheng DH, Chen LF, Mo YQ, Wei XN, et al. Serum matrix metalloproteinase-3 as a noninvasive biomarker of histological synovitis for diagnosis of rheumatoid arthritis. Mediators Inflamm. 2014;2014:179284.

21. Slansky E, Li J, Haupl T, Morawietz L, Krenn V, Pessler F. Quantitative determination of the diagnostic accuracy of the synovitis score and its components. Histopathology. 2010:57:436-43.

22. Krenn V, Morawietz L, Burmester GR, Kinne RW, Mueller-Ladner U, Muller B, et al. Synovitis score: discrimination between chronic low-grade and highgrade synovitis. Histopathology. 2006;49:358-64.

23. Krenn V, Perino G, Rüther W, Krenn VT, Huber $M$, Hügle $T$, et al. 15 years of the histopathological synovitis score, further development and review: a diagnostic score for rheumatology and orthopaedics. Pathol Res Pract. 2017; 213:874-81.

24. Chen LF, Mo YQ, Ma JD, Luo L, Zheng DH, Dai L. Elevated serum lgG4 defines specific clinical phenotype of rheumatoid arthritis. Mediators Inflamm. 2014;2014:635293.

25. Livingston SE, Simonetti JP, MCMahon BJ, Bulkow LR, Hurlburt KJ, Homan CE, et al. Hepatitis B virus genotypes in Alaska native people with hepatocellular carcinoma: preponderance of genotype F. J Infect Dis. 2007; 195:5-11.

26. Saag KG, Teng GG, Patkar NM, Anuntiyo J, Finney C, Curtis JR, et al. American College of Rheumatology 2008 recommendations for the use of nonbiologic and biologic disease-modifying antirheumatic drugs in rheumatoid arthritis. Arthritis Rheum. 2008;59:762-84.

27. Singh JA, Furst DE, Bharat A, Curtis JR, Kavanaugh AF, Kremer JM, et al. 2012 Update of the 2008 American College of Rheumatology recommendations for the use of disease-modifying antirheumatic drugs and biologic agents in the treatment of rheumatoid arthritis. Arthritis Care Res (Hoboken). 2012;64:625-39.

28. Cooper A, Tal G, Lider O, Shaul Y. Cytokine induction by the hepatitis B virus capsid in macrophages is facilitated by membrane heparan sulfate and involves TLR2. J Immunol. 2005;175:3165-76.

29. Kim CW, Yoon SK, Jung ES, Jung CK, Jang JW, Kim MS, et al. Correlation of hepatitis $B$ core antigen and $\beta$-catenin expression on hepatocytes in chronic hepatitis $B$ virus infection: relevance to the severity of liver damage and viral replication. J Gastroenterol Hepatol. 2007;22:1534-42.

30. Hsu HC, Su IJ, Lai MY, Chen DS, Chang MH, Chuang SM, et al. Biologic and prognostic significance of hepatocyte hepatitis B core antigen expressions in the natural course of chronic hepatitis B virus infection. J Hepatol. 1987;5:45-50

31. Chu CM, Liaw YF. Intrahepatic distribution of hepatitis B surface and core antigens in chronic hepatitis B virus infection: hepatocyte with cytoplasmic/ membranous hepatitis B core antigen as a possible target for immune hepatocytolysis. Gastroenterology. 1987;92:220-5.

32. Pontisso P, Vidalino L, Quarta S, Gatta A. Biological and clinical implications of HBV infection in peripheral blood mononuclear cells. Autoimmun Rev. 2008;8:13-7.

33. Bai GQ, Li SH, Yue YF, Shi L. The study on role of peripheral blood mononuclear cell in HBV intrauterine infection. Arch Gynecol Obstet. 2011; 283:317-21.

34. Trepo C, Guillevin L. Polyarteritis nodosa and extrahepatic manifestations of HBV infection: the case against autoimmune intervention in pathogenesis. Autoimmun. 2001;16:269-74.

35. Haringman JJ, Gerlag DM, Zwinderman AH, Smeets TJ, Kraan MC, Baeten D, et al. Synovial tissue macrophages: a sensitive biomarker for response to treatment in patients with rheumatoid arthritis. Ann Rheum Dis. 2005;64:834-8.

36. Yeo L, Toellner KM, Salmon M, Filer A, Buckley CD, Raza K, et al. Cytokine mRNA profiling identifies $B$ cells as a major source of RANKL in rheumatoid arthritis. Ann Rheum Dis. 2011;70:2022-8.

37. Sur CC, Giaglis S, Walker UA, Buser A, Hahn S, Hasler P. Enhanced neutrophi extracellular trap generation in rheumatoid arthritis: analysis of underlying signal transduction pathways and potential diagnostic utility. Arthritis Res Ther. 2014;16:R122.

38. Khandpur R, Carmona-Rivera C, Vivekanandan-Giri A, Gizinski A, Yalavarthi S, Knight JS, et al. NETs are a source of citrullinated autoantigens and stimulate inflammatory responses in rheumatoid arthritis. Sci Transl Med. 2013;5:178ra40

39. Corsiero E, Bombardieri M, Carlotti E, Pratesi F, Robinson W, Migliorini P, et al. Single cell cloning and recombinant monoclonal antibodies generation from RA synovial B cells reveal frequent targeting of citrullinated histones of NETs. Ann Rheum Dis. 2016;75:1866-75

40. Carmona-Rivera C, Carlucci PM, Moore E, Lingampalli N, Uchtenhagen $H$, James $E$, et al. Synovial fibroblast-neutrophil interactions promote pathogenic adaptive immunity in rheumatoid arthritis. Sci Immunol. 2017;2:1-26.

41. Lande R, Ganguly D, Facchinetti V, Frasca L, Conrad C, Gregorio J, et al. Neutrophils activate plasmacytoid dendritic cells by releasing self-DNApeptide complexes in systemic lupus erythematosus. Sci Transl Med. 2011:3:73ra19.

42. Kahlenberg JM, Carmona-Rivera C, Smith CK, Kaplan MJ. Neutrophil extracellular trap-associated protein activation of the NLRP3 inflammasome is enhanced in lupus macrophages. J Immunol. 2013;190:1217-26.

43. Puga I, Cols M, Barra CM, He B, Cassis L, Gentile M, et al. B cell-helper neutrophils stimulate the diversification and production of immunoglobulin in the marginal zone of the spleen. Nat Immunol. 2011;13:170-80.

44. Tillack K, Breiden P, Martin R, Sospedra M. T lymphocyte priming by neutrophil extracellular traps links innate and adaptive immune responses. J Immunol. 2012;188:3150-9.

45. Scully $\sqcup$, Karayiannis $P$, Thomas HC. Interferon therapy is effective in treatment of hepatitis B-induced polyarthritis. Dig Dis Sci. 1992;37:1757-60.

46. Csepregi A, Rojkovich B, Nemesanszky E, Poor G, Hejjas M, Horanyi M. Chronic seropositive polyarthritis associated with hepatitis B virus-induced chronic liver disease: a sequel of virus persistence. Arthritis Rheum. 2000;43:232-3.

47. Hepatitis B vaccine recombinant: Rheumatoid arthritis?: case report. Reactions.1994;1:9. 